\title{
La Fable orientale. Regards sur le Moyen-Orient à l'âge classique (1630-1780), dir. Ch. MARTIN, L. NORCI CAGIANO et L. PLAZENET
}

\section{Monica Pavesio}

\section{OpenEdition}

\section{Journals}

\section{Edizione digitale}

URL: https://journals.openedition.org/studifrancesi/45023

DOI: 10.4000/studifrancesi.45023

ISSN: 2427-5856

\section{Editore}

Rosenberg \& Sellier

\section{Edizione cartacea}

Data di pubblicazione: 1 août 2021

Paginazione: $370-371$

ISSN: 0039-2944

\section{Notizia bibliografica digitale}

Monica Pavesio, «La Fable orientale. Regards sur le Moyen-Orient à l'âge classique (1630-1780), dir. Ch. MARTIN, L. NORCI CAGIANo et L. PLAZENET», Studi Francesi [Online], 194 (LXV | II) | 2021, online dal 01 septembre 2021, consultato il 15 octobre 2022. URL: http://journals.openedition.org/studifrancesi/ 45023 ; DOI: https://doi.org/10.4000/studifrancesi.45023

Questo documento è stato generato automaticamente il 15 octobre 2022

\section{(c) $($ ) $(9)$}

Creative Commons - Attribuzione - Non commerciale - Non opere derivate 4.0 Internazionale - CC BYNC-ND 4.0

https://creativecommons.org/licenses/by-nc-nd/4.0/ 


\title{
La Fable orientale. Regards sur le Moyen-Orient à l'âge classique (1630-1780), dir. Ch. MARTIN, L. NORCI CAGIANO et L. PLAZENET
}

\author{
Monica Pavesio
}

\section{NOTIZIA}

La Fable orientale. Regards sur le Moyen-Orient à l'âge classique (1630-1780), dir. Ch. MARTIN, L. NORCI CAGIANO et L. PLAZENET, Paris, Hermann, 2019, «Fictions pensantes», 190 pp.

1 La miscellanea di studi, che riunisce gli atti del Convegno internazionale organizzato nel 2017 dall'Università di Roma Tre, dal CNRS e dalla facoltà di Lettere della Sorbonne, vuole indagare il rapporto indissolubile che si viene a creare tra il XVII e XVIII secolo tra l'Oriente e il genere della favola. Come illustra C. MARTIN nell'Introduction, le relazioni commerciali e diplomatiche (in particolare con l'Impero Ottomano) e la conseguente produzione di diari di viaggio contribuirono alla migliore conoscenza del MedioOriente. Iniziò così a svilupparsi il fenomeno dell'orientalismo, che avrà poi la sua massima diffusione nel xvIII secolo. All'Oriente biblico si sostituiscono, poco per volta, rappresentazioni inedite, che il romanzo e il teatro non tardano ad utilizzare. I saggi riuniti nella miscellanea, non esaminano solo le motivazioni che hanno spinto il pensiero occidentale ad imputare all'immaginazione degli orientali l'origine della favola, ma si interrogano, più in generale, sui modi in cui l'immaginario occidentale ha riletto, riscritto e reinterpretato l'Oriente. Almeno per quanto riguarda il xvII secolo, sembra manifestarsi, come emerge dai saggi riuniti nel volume, l'immagine di un Oriente caratterizzato da tratti vaghi e convenzionali, da un'ambivalenza fondamentale a metà tra locus amœnus e locus terribilis. 
Il volume, che contiene saggi di specialisti del XVII e XVIII secolo, è diviso in tre sezioni. Segnaleremo in questa sede solo gli studi relativi ad autori e problematiche secentesche.

3 La prima parte, intitolata «Usages de la Fable orientale à l'âge classique», riunisce alcuni contributi sulle modalità d'utilizzo della favola orientale nel periodo preso in esame. Si apre con lo studio di AURELIO PRINCIPATO ("De Turc à More": à la recherche de la diversité orientale avant l'orientalisme, pp. 25-43) che analizza la prima fase delle relazioni tra le civiltà del Mediterraneo, il momento in cui il mondo cristiano e musulmano si incontrano ed in cui la cultura araba entra in Europa. Il successivo saggio di FEDERICO CORRADI (Une exemple d'assimilation culturelle: la fable orientale dans le "Traité de l'origine des romans" de Pierre-Daniel Huet, pp. 45-60) illustra come il trattato di Huet, pubblicato nel 1670 , sia un tassello essenziale nel processo che ha portato all'elaborazione dell'orientalismo, così importante nella successiva cultura dei Lumi. Lo studio di PATRICK DANDREY (La Fontaine et ses fables "orientales": une fiction d'altérité? pp. 61-76) cerca e spiega l'orientalismo nelle favole di La Fontaine. CAMILLE ESMEIN-SARRAZIN (Zayde une fable orientale? pp.77-92) analizza la funzione del quadro orientale nel romanzo Zayde di Mme de La Fayette e la sua ricezione secentesca e settecentesca. Nel saggio L'Orient des moralistes (pp. 93-111), LAURENCE PLAZENET si interroga sulle motivazioni che generarono il disinteresse dei moralisti secenteschi nei confronti dell'Oriente e della favola orientale.

4 La seconda parte del volume, "Aux frontières du Conte oriental», è incentrata sulla presenza di elementi orientali nella produzione secentesca e settecentesca del Conte. BENEDETTA PAPASOGLI ("Histoire d'Alibrée, persan": Fénelon à l'epreuve du conte oriental, pp. 115-130), si chiede se la favola pedagogica di Fénelon del 1690, Histoire d'Alibrée, persan, possa essere considerata un conte orientale ed illustra poi come l'autore utilizzi il dispositivo del conte orientale, dopo averlo ripulito dei suoi elementi esotici.

L'ultima sezione, intitolata «La fable orientale sur la scène et dans les arts», è dedicata al teatro e alle arti. RACHEL LAUTHELIE-MOURIER (Comment des répresentations historiques peuvent-elles rendre aveugle à la réalité du temps?, pp. 191-208) ripercorre la diffusione delle rappresentazioni dei due eroi dell'antichità persiana, Ciro, fondatore dell'Impero, e Pantea, regina di Susa, le cui vite sono state romanzate in Occidente, fino a diventare miti letterari. DANIELA DALLA VALLE ("Osman" de Tristan l'Hermite: un modèle de tragédie ottomane, pp. 209-226) illustra come Tristan nel 1656 si serva di fonti storiche per comporre Osman, ma utilizzi poi rappresentazioni stereotipate dei costumi orientali che suscitino il terrore nell'immaginario francese dell'epoca. VALERIA POMPEJANO (Le costume oriental sur la scène et dans les romans baroques, pp. 227-241) sottolinea, più in generale, che se la curiosità per l'Oriente si manifesta fin dagli anni Venti del secolo con le relazioni di viaggio, i tratti dei personaggi orientali sulla scena e nei romanzi barocchi restano associati alla crudeltà, alla duplicità ed alla furbizia. 